\title{
Seismic Behaviors of the Composite Central Brace with Steel Ring Damper
}

\author{
Xiao-Tong PENG ${ }^{1, a}$, Chen LIN $^{2, b}$,Yong-Ming CAO ${ }^{1, c}$, Wen-Xu DUAN ${ }^{1, d}$ \\ ${ }^{1}$ School of Civil Engineering and Architecture, University of Jinan, Jinan 250022, China \\ ${ }^{2}$ School of Architecture and Landscape Design, Shandong University of Art \& Design, Jinan \\ 250014, China

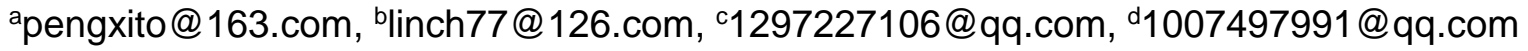

\begin{abstract}
Keywords: Central brace; Energy-dissipation ring; Finite element; Design method
Abstract. Using ring damper in the center brace could solve premature buckling and decrease residual deformation of the central brace. A design method for Composite Steel Ring Brace system was proposed based on current design codes. A nonlinear finite element model was established to study seismic behaviors of the ring damper by use of ABAQUS software. The results indicate that ring damper has ample initial stiffness, bearing capacity, better deformation performance and energy dissipation ability in the control displacement range.
\end{abstract}

\section{Introduction}

The brace can significantly improve the lateral stiffness of steel frame. Pure steel brace has the characteristics of easy buckling instability and weak energy dissipation performance, which cannot meet the seismic requirements. In order to resolve the problem mentioned above, Jun xian Zhao ${ }^{[1-4]}$ have conducted researches on various types of brace system, and the research results can improve the buckling of supports to a certain extent, but the residual deformation is still large after the earthquake. Canadian scholar Robert ${ }^{[5-6]}$ settled the problem of large post-earthquake deformation by conducting tensile test on a new type of self-reduction energy-consuming brace with dual characteristics of self-reduction and energy consumption. This kind of brace has high requirements on prestressed bars, which is difficult to realize in real practice. In order to make up the shortcomings of the traditional braces, a composite central brace with steel ring damper (CBRD) is produced. The existence of the ring damper could improve the seismic performance of the brace. Based on the current design specifications, a design method for CBRD system is put forward, which enlarge the use of the central brace.

\section{Design of CBRD system}

The calculating example is based on a 6-storey frame-brace structure. The total lateral force is calculated by using the bottom shear method. The lateral force of selected frame is evaluated by $1 / 3$ of the total lateral force, the interlayer shear force is calculated by the sum of force of above layers and (Table 1).

Table 1.Interlayer Shear Force

\begin{tabular}{ccccccc}
\hline Number of layers $/ i$ & 1 & 2 & 3 & 4 & 5 & 6 \\
\hline interlayer shear $V_{i} / \mathrm{KN}$ & 1112.9 & 1058.8 & 951.6 & 793.3 & 577.2 & 321.1
\end{tabular}

The brace of the combined ring is equivalent to the central herringbone system, which is assumed to bear all the lateral shear. Consider the angular relationship between the shear force between layers and the equivalent brace, the maximum axial force of the bottom layer is calculated to be $1043.3 \mathrm{KN}$.

\section{Ring damper design}

Based the simplified force analysis Figure 1, the bearing capacity of the ring damper is calculated by the axial force caused by the interlayer shear force to meet the requirements of deformation. 
Through the plastic hinge Pi bending moment equilibrium conditions, the thickness of the ring is 12 $\mathrm{mm}$, and its overhanging plates length is $180 \mathrm{~mm}$. The inner and outer radius of the ring damper is set as $99 \mathrm{~mm}$ and $105 \mathrm{~mm}$ respectively.

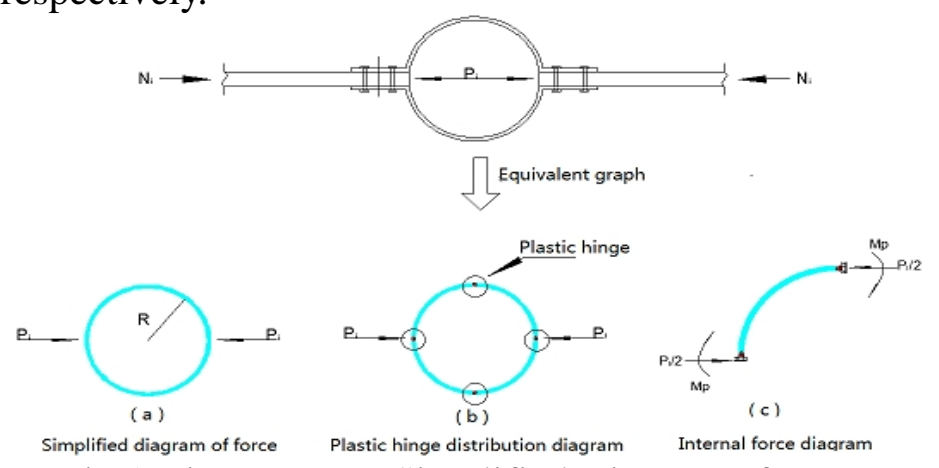

Fig.1 Ring Damper Simplified Diagram of Force

According to Zahra Andalib ${ }^{[7]}$ studies' on the bearing capacity and energy dissipation performance of a composite steel damper, the ring damper is actually difficult to realize it's the ideal state, thus there is an error between theoretical value and real value. A adjustment factor should be considered, and the calculation formula for the bearing capacity of the ring in the elastic range and the plastic range (Equation 1,2) is proposed.

$$
\begin{array}{ll}
\mathrm{K}_{1}=\mathrm{l}_{\mathrm{i}}^{2} / 3 \mathrm{t}_{\mathrm{i}} \mathrm{R}_{\mathrm{i}} & \mathrm{P}_{\mathrm{i}}=\mathrm{K}_{1} \pi \mathrm{t}_{\mathrm{i}}^{2} \mathrm{l}_{\mathrm{i}} \mathrm{f}_{\mathrm{y}} / \mathrm{R}_{\mathrm{i}} \\
\mathrm{K}_{2}=\mathrm{l}_{\mathrm{i}}^{2} / 2 \mathrm{t}_{\mathrm{i}} \mathrm{R}_{\mathrm{i}} & \mathrm{P}_{\mathrm{i}}=\mathrm{K}_{2} \pi \mathrm{t}_{\mathrm{i}}^{2} \mathrm{l}_{\mathrm{i}} \mathrm{f}_{\mathrm{y}} / \mathrm{R}_{\mathrm{i}}
\end{array}
$$

Where,

$\mathrm{K}_{1----}$ Elastic section composite ring bearing capacity adjustment factor;

$\mathrm{K}_{2----}$ Plastic section composite ring bearing capacity adjustment factor;

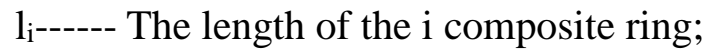

$\mathrm{t}_{\mathrm{i}------}$ The thickness of the $\mathrm{i}$ composite ring;

$\mathrm{R}_{\mathrm{i}^{-----}}$The radius of the $\mathrm{i}$ composite ring.

The compression bearing capacity of the ring damper is $121.7 \mathrm{KN}$, which is close to the design value of the theoretical ultimate bearing capacity of $117.2 \mathrm{KN}$. the calculation error is about $3 \%$.

\section{Connection design of brace rod}

As shown in figure2, Using groove butt joint design could achieve connection of inner sleeve. According to the specifications of steel structure for high-rise buildings (JGJ99-2015) ${ }^{[8]}$, the dimension of the section are calculated as $90 \mathrm{~mm}$ and $120 \mathrm{~mm}$ respectively. Based on the "Code for Design of Steel Structures" ${ }^{[9]}$ (GB50017-2017), the connection design of the brace bar was carried out. The ring damper is bolted to the brace. The diameter of the bolt is $22.8 \mathrm{~mm}$ according to the shear capacity design of the bolt. The bolts of the brace are arranged along the length of the supporting rods, with $90 \mathrm{~mm}$ space. The End bolts are $24 \mathrm{~mm}$ distance from the edge. The cover plate is welded to the upper port of the lower brace. The butt weld is E43 electrode, the fillet weld is E50 electrode, the welding leg size is $6 \mathrm{~mm}$, and the weld strength is designed to meet the specification requirements.

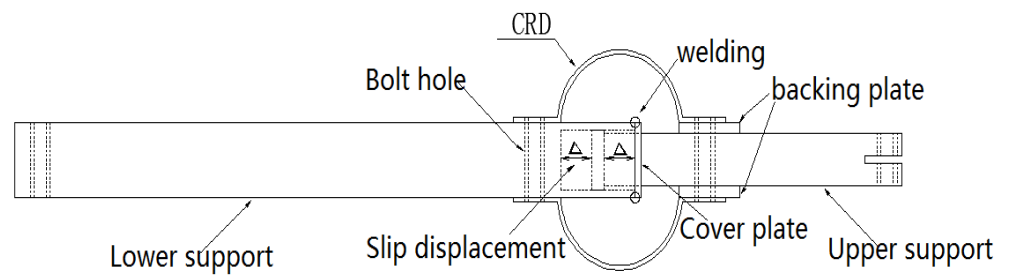

Fig.2 Inner Sleeve Connection

\section{Finite Element Analysis}

Finite Element Modeling

In order to simulate the ring damper accurately, the element C3D8R hexahedron solid unit is 
adopted, as shown in figure3. Q235B grade steel is applied for the ring damper. The yield stress and elastic modulus are respectively $197 \mathrm{Mpa}$ and $203 \mathrm{Gpa}$. In the model, the method of "face to face hard contact" is used to simulate the contact situation of the two plates.

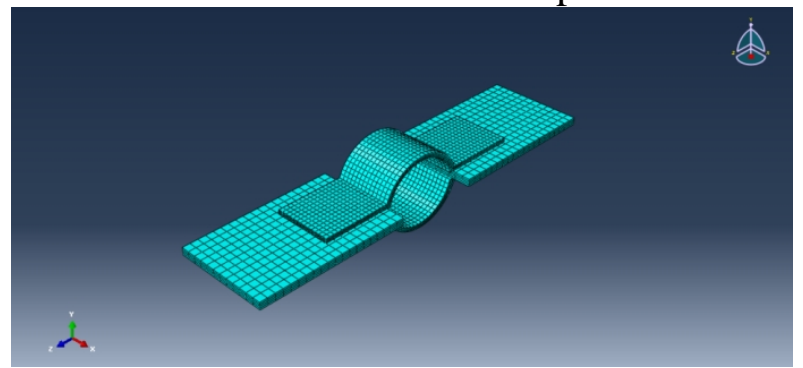

Fig.3 Ring Damper Finite Element Model

\section{Finite element analysis}

\section{Behavior under monotonic loading}

As shown in Figure4-5, the ring damper were experienced elastic, yield and elastic-plastic under tension and compression. The simulation results were compared with that of Yun Zhou ${ }^{[10-11]}$ and Ji Liu (Table 2). The Bearing capacity under tension is 10 times higher than that under compression. Whereas the stiffness is almost the same.

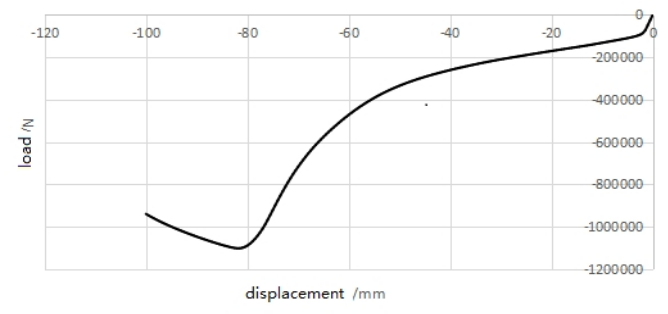

Figure.4 The Curve under the Tensile Load

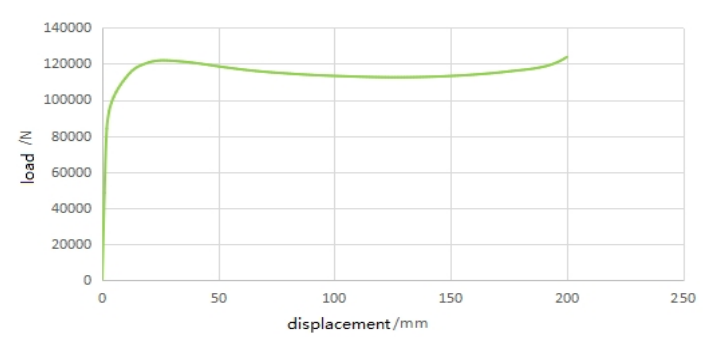

Figure.5 The Curve under the Compress Load Table 2 .Comparison of Bearing Capacity and Stiffness

\begin{tabular}{ccc}
\hline Loading mode & Bearing capacity & Stiffness \\
\hline Ring damper & $121.7 \mathrm{KN}$ & $48.3 \mathrm{KN} / \mathrm{mm}$ \\
Flat plate damper $^{[10]}$ & $18.9 \mathrm{KN}$ & $1.2 \mathrm{KN} / \mathrm{mm}$ \\
Double ring damper $^{[11]}$ & $50.4 \mathrm{KN}$ & $4.8 \mathrm{KN} / \mathrm{mm}$ \\
\hline
\end{tabular}

\section{Seismic behavior}

As shown in Figure 6, the hysteretic curve has good performance within the range of $30 \mathrm{~mm}$. The energy dissipation of the ring damper is mainly caused by plastic hinges in the range of $30 \mathrm{~mm}$ displacement. The plastic hinges mainly appears at the top and sides of the ring damper.

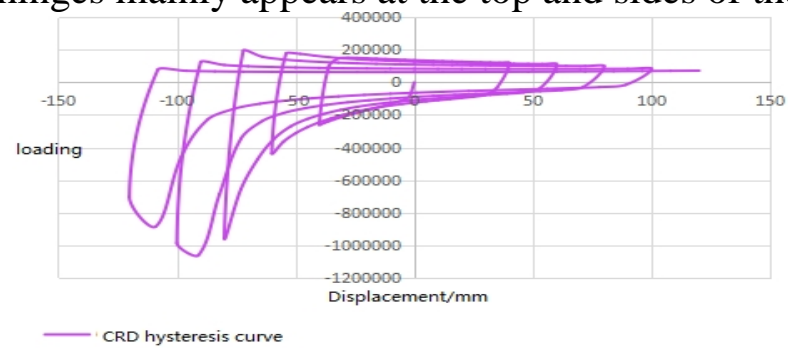

Fig.6 Hysteretic Curve

\section{Conclusions}

1.The ring damper is designed by use of conjunction of bolt and weld to meet the initial rigidity and seismic demands.

3.The ring damper can be used as an energy dissipation component for central braces. It absorbs the earthquake energy and avoid the premature buckling of the brace.

3.The ring damper reaches the ultimate bearing capacity through forms of multi-plastic hinges, and 
shows good seismic performance within the $30 \mathrm{~mm}$ ranges.

\section{Acknowledgements}

The work was sponsored by Key Research and Development Program of Shandong Province (2015GSF122003; 2016GSF122012). The writers gratefully acknowledge the support provided and a Project of Shandong Province Higher Educational Science and Technology Program(J17KB048; J18KA208).

\section{References}

[1]Ming Jia, Su mei Zhang. Analysis of hysteretic behavior of restraining buckling support [J]. Journal of tian jin university,2008,41(6):736-744.

[2]Xiang yu Gao, Hai yan Du, Hui Zhang, et al. Seismic performance test study on anti-buckling support of hot rolled steel in national standard Q235 [J]. Architectural structure,2008,38(3):91-95.

[3]Sridhara, B. N. Sleeved column-as a basic compression member [A]. Proceedings, 4th International Conference on Steel Structures a Space Frames[C]: Singapore, 1990,181-188.

[4]Jun xian Zhao, Bin $\mathrm{Wu}$, Jin ping Ou. Quasi-static hysteresis performance test of new type anti-buckling support for all steel [J]. Journal of civil engineering,2011,44(4):60-70.

[5]R.Tremblay, H.-J.Kim, M.Lacerte. Self-Centering Energy Dissipative Bracing System for the Seismic Resistance of Structures: Development and Validation. Journal of Structural Engineering.2008,134(1): 96-107.

[6]Osman E. Ozbulut. Stefan Hurlebaus. Application of an SMA-based hybrid control device to 20-story nonlinear benchmark building[J].Earthquake Engineering and Structural Dynamics,2012,41(13) : 1831-1843.

[7] Industrial standards of the People's Republic of China. Technical specifications for steel structure in high-rise civil buildings (JGJ99) [S]. Beijing: China building industry press,2015.

[8]Zahra Andalib, Mohammad Ali Kafi. Experimental investigation of the ductility and performance of steel rings constructed from plates[J].Journal of Construction Steel Research, 2014 , (7) : 78 88.

[9]National standards of the People's Republic of China. Specification for steel structure design (gb50017-2003) [S]. Beijing: China plan press,2003.

[10]Yun Zhou, Ji Liu. Development and research of new damper[J]. World earthquake engineering,1998,18(1):71-78.

[11]Feng Sun, Yun Zhou, et al. Experimental study on the performance of stiffening ring damper [J]. Seismic engineering and engineering vibration,1999,19(3):115-120. 